«Системні технології» 5 (130) 2020 «System technologies»

DOI 10.34185/1562-9945-5-130-2020-01

UDC 681.518

G.G. Diachenko, O.O. Aziukovskyi

\title{
A CONTINUOUS ENERGY-EFFICIENCY OPTIMIZATION CONTROLLER FOR FIELD-ORIENTATION INDUCTION MOTOR DRIVES
}

Abstract. The current paper discusses the adaptive choice of a filter time constant for filtering the steady-state flux reference in the energy-efficient control problem of field-orientation induction machines in transient behavior when load and speed conditions are changing taking into account the effect of the main induction saturation. It is shown that by appropriately managing the flux linkage rate of change the energy losses per full operation cycle under torque changes can be significantly reduced compared to the conventional cases. The analysis for the appropriate choice of the filter time constant as a fraction of the rotor time constant is based on a numerical study and simulation results for three different induction machines with different rated powers.

Keywords: energy efficiency, power loss, filtering, adaptive search, dynamic operation

\section{Statement of the problem and analysis of the recent research and} publications. The induction machine is widely used in industrial applications due to its robustness and its low cost compared to permanent magnet synchronous machines. However, in part-load operation, the efficiency of the induction machine dramatically decreases when the flux is kept at the nominal level. To address this issue different strategies have been developed in the past to increase the efficiency of the induction machine in a large operation range [1],[2]. However, when the induction machine is operated under changing loads these methods will not yield maximum efficiency. A solution to this problem in the framework of vehicle applications is given in [3]. However, the motor for these applications will often operate in dynamics with changing torques and speed up to voltage and current limits. The development of parametrized prototypes is discussed in [4]. Unfortunately, without voltage and current limits as well. These limits require the knowledge of the behavior of the process quantities, which can be obtained from offline optimization [5].

(C) Diachenko G.G., Aziukovskyi O.O., 2020 
«Системні технології» 5 (130) 2020 «System technologies»

Purpose of the study. The current paper discusses a different approach. The motivation is to give a simple and easy implementable solution to the problem of energy consumption minimization, which is characterized by a continuity of action, converges to the optimal flux level in the steadystate and expresses a compromise approach to the problem with changing loads in dynamics as well as provide an alternative solution to model predictive control [6].

Statement of main research material. State-space model. An induction machine operated with high dynamics is controlled as a rule via a field-oriented scheme. The approach in the sequel implies the orientation along the rotor flux linkage $\Psi_{2}$, i.e. the flux linkage phasor is aligned with the $\mathrm{d}$-axis of the rotating frame. The full model thus has four state variables: field-producing current $i_{1 \mathrm{~d}}$, torque-producing current $i_{1 \mathrm{q}}$, rotor flux $\Psi_{2}$, and motor speed $\omega_{2}$; and two controls: the stator voltage phasor components $u_{1 \mathrm{~d}}$ and $u_{1 q}$. The continuous state-space model of an induction machine is given as follows ( $\Gamma$-inverse equivalent circuit parameters are used):

$$
\left\{\begin{array}{c}
\dot{\mathrm{x}}=\mathrm{A}(\mathrm{x}) \mathrm{x}+\mathrm{Bu}+\delta \\
\mathrm{y}=\mathrm{Cx}
\end{array}\right.
$$

with state $\mathrm{x} \in \mathbb{R}^{(4 \times 1)}$ represented by $\mathrm{x}=\left[\begin{array}{llll}i_{1 \mathrm{~d}} & i_{1 \mathrm{q}} & \Psi_{2} & \omega_{2}\end{array}\right]^{\mathrm{T}}$ and control $\mathrm{u} \in \mathbb{R}^{(2 \times 1)}$ consisting of the terminal voltages, given by $\mathrm{u}=\left[\begin{array}{ll}u_{1 \mathrm{~d}} & u_{1 \mathrm{q}}\end{array}\right]^{\mathrm{T}} ; \delta \in \mathbb{R}^{(4 \times 1)}$ is a disturbance vector, given by $\delta=\left[\begin{array}{lllll}0 & 0 & 0 & Z_{\mathrm{p}}\left(T_{\mathrm{e}}-T_{\text {load }}\right) / J\end{array}\right]^{\mathrm{T}}$, with $J$ denoting the total moment of inertia of the rotating couplings, $Z_{\mathrm{p}}$ is the number of pole pairs, $T_{\mathrm{e}}$ and $T_{\text {load }}$ are motor and load torque, respectively; and $\mathrm{A}(\mathrm{x}) \in \mathbb{R}^{(4 \times 4)}$ is the characteristic matrix of the system, given by the following expression

$$
\mathrm{A}=\left[\begin{array}{cccc}
-\left(R_{1}+R_{2}\right) / L_{\sigma} & \omega_{1} & R_{2} /\left(L_{m} L_{\sigma}\right) & 0 \\
-\omega_{1} & -R_{2} / L_{\sigma} & -\omega_{1} / L_{\sigma} & 0 \\
R_{2} & 0 & -R_{2} / L_{m} & 0 \\
0 & 0 & 0 & 0
\end{array}\right]
$$

with stator and rotor resistances $R_{1}$ and $R_{2}$ respectively; $\mathrm{L}_{\sigma}$ is the stray inductance and $L_{\mathrm{m}}$ denotes the main inductance; and $\omega_{1}$ as the synchronous speed in electrical radians per second, obtained from 
«Системні технології» 5 (130) 2020 «System technologies»

$$
\omega_{1}=\omega_{2}+\omega_{\text {slip }}=\omega_{2}+R_{2} \frac{i_{1 q}}{\Psi_{2}}
$$

where $\omega$ slip is the slip speed. $\mathrm{B} \in \mathbb{R}^{(4 \times 2)}$ is the input matrix given by

$$
\mathrm{B}=\left[\begin{array}{cc}
1 / L_{\sigma} & 0 \\
0 & 1 / L_{\sigma} \\
0 & 0 \\
0 & 0
\end{array}\right] .
$$

$\mathrm{y} \in \mathbb{R}^{(2 \times 1)}$ is the outputs vector given by $\mathrm{y}=\left[\begin{array}{ll}\Psi_{2} & \omega_{2}\end{array}\right]^{\mathrm{T}}$; the matrix of outputs $\mathrm{C} \in \mathbb{R}^{(2 \times 4)}$ is given by

$$
C=\left[\begin{array}{llll}
0 & 0 & 1 & 0 \\
0 & 0 & 0 & 1
\end{array}\right] .
$$

The electromagnetic torque is given by

$$
T_{\mathrm{e}}=\frac{3}{2} Z_{\mathrm{p}} \Psi_{2} i_{1 \mathrm{q}}
$$

Main inductance saturation. The modelling of an induction machine to be adequate must consider the nonlinear nature of the machine magnetic characteristics. The measured main inductance data points are shown in Fig. 1. The minimum allowable set consists of 5-6 points. In addition, with a small amount of data, "abnormal" results cannot be included in the sampling sequence. Hence, the bigger the number of points, the better. The experimentally measured data of nineteen points is further approximated using the method of least squares. An obvious "applicant” immediately appears here in a form of a high-degree polynomial whose curve passes through all measured points. But this option is, more often than not, simply incorrect and reflects the main trend poorly. Thus, the desired function should be relatively simple and at the same time reflect the dependence adequately. We will restrict the degree of resulting polynomial to fifth degree. In this case, the objective consists of adjusting the parameters of a model function $L_{\mathrm{m}}\left(i_{1 \mathrm{~d}}\right): \mathbb{R} \rightarrow \mathbb{R}, \forall i_{1 \mathrm{~d}} \in \mathbb{R}$. To fit the model to a data it is required to find the optimal parameter values by minimizing the sum of squared residuals given in the following form 
«Системні технології» 5 (130) 2020 «System technologies»

$\min _{\sum_{k=1}^{n} r_{k}^{2}} F\left(P_{1}, P_{2}, P_{3}, P_{4}, P_{5}, P_{6}\right)=\sum_{k=1}^{n}\left[Y_{\mathrm{k}}-\left(P_{1} \lambda_{\mathrm{k}}^{5}+P_{2} \lambda_{\mathrm{k}}^{4}+P_{3} \lambda_{\mathrm{k}}^{3}+P_{4} \lambda_{\mathrm{k}}^{2}+P_{5} \lambda_{\mathrm{k}}+P_{6}\right)\right]^{2}$

s.t. $\lambda_{\mathrm{k}} \in\left[\lambda^{-}, \lambda^{+}\right]$

where $P_{1}-P_{6}$ are the function parameter values to be found; $\lambda_{\mathrm{k}}$ and $Y_{\mathrm{k}}$ are measured field-producing current and main inductance values, respectively.

In essence, it is necessary to solve the problem of finding the minimum of the function of six variables. First things first, let us find all partial derivatives of the first order. According to the rule of linearity, it is allowed to differentiate under the sum sign:

$$
\begin{aligned}
& \frac{\partial F}{\partial P_{1}}=2 \sum_{\mathrm{k}=1}^{n}\left(P_{1} \lambda_{\mathrm{k}}^{10}+P_{2} \lambda_{\mathrm{k}}^{9}+P_{3} \lambda_{\mathrm{k}}^{8}+P_{4} \lambda_{\mathrm{k}}^{7}+P_{5} \lambda_{\mathrm{k}}^{6}+P_{6} \lambda_{\mathrm{k}}^{5}-\lambda_{\mathrm{k}}^{5} Y_{\mathrm{k}}\right) \\
& \frac{\partial F}{\partial P_{2}}=2 \sum_{\mathrm{k}=1}^{n}\left(P_{1} \lambda_{\mathrm{k}}^{9}+P_{2} \lambda_{\mathrm{k}}^{8}+P_{3} \lambda_{\mathrm{k}}^{7}+P_{4} \lambda_{\mathrm{k}}^{6}+P_{5} \lambda_{\mathrm{k}}^{5}+P_{6} \lambda_{\mathrm{k}}^{4}-\lambda_{\mathrm{k}}^{4} Y_{\mathrm{k}}\right) \\
& \frac{\partial F}{\partial P_{3}}=2 \sum_{\mathrm{k}=1}^{n}\left(P_{1} \lambda_{\mathrm{k}}^{8}+P_{2} \lambda_{\mathrm{k}}^{7}+P_{3} \lambda_{\mathrm{k}}^{6}+P_{4} \lambda_{\mathrm{k}}^{5}+P_{5} \lambda_{\mathrm{k}}^{4}+P_{6} \lambda_{\mathrm{k}}^{3}-\lambda_{\mathrm{k}}^{3} Y_{\mathrm{k}}\right) \\
& \frac{\partial F}{\partial P_{4}}=2 \sum_{\mathrm{k}=1}^{n}\left(P_{1} \lambda_{\mathrm{k}}^{7}+P_{2} \lambda_{\mathrm{k}}^{6}+P_{3} \lambda_{\mathrm{k}}^{5}+P_{4} \lambda_{\mathrm{k}}^{4}+P_{5} \lambda_{\mathrm{k}}^{3}+P_{6} \lambda_{\mathrm{k}}^{2}-\lambda_{\mathrm{k}}^{2} Y_{\mathrm{k}}\right) \\
& \frac{\partial F}{\partial P_{5}}=2 \sum_{\mathrm{k}=1}^{n}\left(P_{1} \lambda_{\mathrm{k}}^{6}+P_{2} \lambda_{\mathrm{k}}^{5}+P_{3} \lambda_{\mathrm{k}}^{4}+P_{4} \lambda_{\mathrm{k}}^{3}+P_{5} \lambda_{\mathrm{k}}^{2}+P_{6} \lambda_{\mathrm{k}}-\lambda_{\mathrm{k}} Y_{\mathrm{k}}\right) \\
& \frac{\partial F}{\partial P_{6}}=2 \sum_{\mathrm{k}=1}^{n}\left(P_{1} \lambda_{\mathrm{k}}^{5}+P_{2} \lambda_{\mathrm{k}}^{4}+P_{3} \lambda_{\mathrm{k}}^{3}+P_{4} \lambda_{\mathrm{k}}^{2}+P_{5} \lambda_{\mathrm{k}}+P_{6}-Y_{\mathrm{k}}\right)
\end{aligned}
$$

Now compose a typical system equating each expression from (8) to 0 . Then divide each equation by two and, in addition, split the sums: 
«Системні технології» 5 (130) 2020 «System technologies»

$$
\left\{\begin{array}{l}
P_{1} \sum_{\mathrm{k}=1}^{n} \lambda_{\mathrm{k}}^{10}+P_{2} \sum_{\mathrm{k}=1}^{n} \lambda_{\mathrm{k}}^{9}+P_{3} \sum_{\mathrm{k}=1}^{n} \lambda_{\mathrm{k}}^{8}+P_{4} \sum_{\mathrm{k}=1}^{n} \lambda_{\mathrm{k}}^{7}+P_{5} \sum_{\mathrm{k}=1}^{n} \lambda_{\mathrm{k}}^{6}+P_{6} \sum_{\mathrm{k}=1}^{n} \lambda_{\mathrm{k}}^{5}=\sum_{\mathrm{k}=1}^{n} \lambda_{\mathrm{k}}^{5} Y_{\mathrm{k}} \\
P_{1} \sum_{\mathrm{k}=1}^{n} \lambda_{\mathrm{k}}^{9}+P_{2} \sum_{\mathrm{k}=1}^{n} \lambda_{\mathrm{k}}^{8}+P_{3} \sum_{\mathrm{k}=1}^{n} \lambda_{\mathrm{k}}^{7}+P_{4} \sum_{\mathrm{k}=1}^{n} \lambda_{\mathrm{k}}^{6}+P_{5} \sum_{\mathrm{k}=1}^{n} \lambda_{\mathrm{k}}^{5}+P_{6} \sum_{\mathrm{k}=1}^{n} \lambda_{\mathrm{k}}^{4}=\sum_{\mathrm{k}=1}^{n} \lambda_{\mathrm{k}}^{4} Y_{\mathrm{k}} \\
P_{1} \sum_{\mathrm{k}=1}^{n} \lambda_{\mathrm{k}}^{8}+P_{2} \sum_{\mathrm{k}=1}^{n} \lambda_{\mathrm{k}}^{7}+P_{3} \sum_{\mathrm{k}=1}^{n} \lambda_{\mathrm{k}}^{6}+P_{4} \sum_{\mathrm{k}=1}^{n} \lambda_{\mathrm{k}}^{5}+P_{5} \sum_{\mathrm{k}=1}^{n} \lambda_{\mathrm{k}}^{4}+P_{6} \sum_{\mathrm{k}=1}^{n} \lambda_{\mathrm{k}}^{3}=\sum_{\mathrm{k}=1}^{n} \lambda_{\mathrm{k}}^{3} Y_{\mathrm{k}} \\
P_{1} \sum_{\mathrm{k}=1}^{n} \lambda_{\mathrm{k}}^{7}+P_{2} \sum_{\mathrm{k}=1}^{n} \lambda_{\mathrm{k}}^{6}+P_{3} \sum_{\mathrm{k}=1}^{n} \lambda_{\mathrm{k}}^{5}+P_{4} \sum_{\mathrm{k}=1}^{n} \lambda_{\mathrm{k}}^{4}+P_{5} \sum_{\mathrm{k}=1}^{n} \lambda_{\mathrm{k}}^{3}+P_{6} \sum_{\mathrm{k}=1}^{n} \lambda_{\mathrm{k}}^{2}=\sum_{\mathrm{k}=1}^{n} \lambda_{\mathrm{k}}^{2} Y_{\mathrm{k}} \\
P_{1} \sum_{\mathrm{k}=1}^{n} \lambda_{\mathrm{k}}^{6}+P_{2} \sum_{\mathrm{k}=1}^{n} \lambda_{\mathrm{k}}^{5}+P_{3} \sum_{\mathrm{k}=1}^{n} \lambda_{\mathrm{k}}^{4}+P_{4} \sum_{\mathrm{k}=1}^{n} \lambda_{\mathrm{k}}^{3}+P_{5} \sum_{\mathrm{k}=1}^{n} \lambda_{\mathrm{k}}^{2}+P_{6} \sum_{\mathrm{k}=1}^{n} \lambda_{\mathrm{k}}=\sum_{\mathrm{k}=1}^{n} \lambda_{\mathrm{k}} Y_{\mathrm{k}} \\
P_{1} \sum_{\mathrm{k}=1}^{n} \lambda_{\mathrm{k}}^{5}+P_{2} \sum_{\mathrm{k}=1}^{n} \lambda_{\mathrm{k}}^{4}+P_{3} \sum_{\mathrm{k}=1}^{n} \lambda_{\mathrm{k}}^{3}+P_{4} \sum_{\mathrm{k}=1}^{n} \lambda_{\mathrm{k}}^{2}+P_{5} \sum_{\mathrm{k}=1}^{n} \lambda_{\mathrm{k}}+n P_{6}=\sum_{\mathrm{k}=1}^{n} Y_{\mathrm{k}}
\end{array}\right.
$$

The obtained system (9) can be solved, for example, by Cramer's rule, and as a result, a stationary point is obtained $F\left(P_{1}^{*}, P_{2}^{*}, P_{3}^{*}, P_{4}^{*}, P_{5}^{*}, P_{6}^{*}\right)$. By checking the sufficient condition for the extremum, we can verify that at exactly this point the function reaches its minimum. The check is connected with additional calculations and therefore it is left behind the scenes. The function with $F(-0.669,3.606,-6.622,4.415,-0.743,0.754)$ in the best way (at least in comparison with any other function) approximates the experimental points.

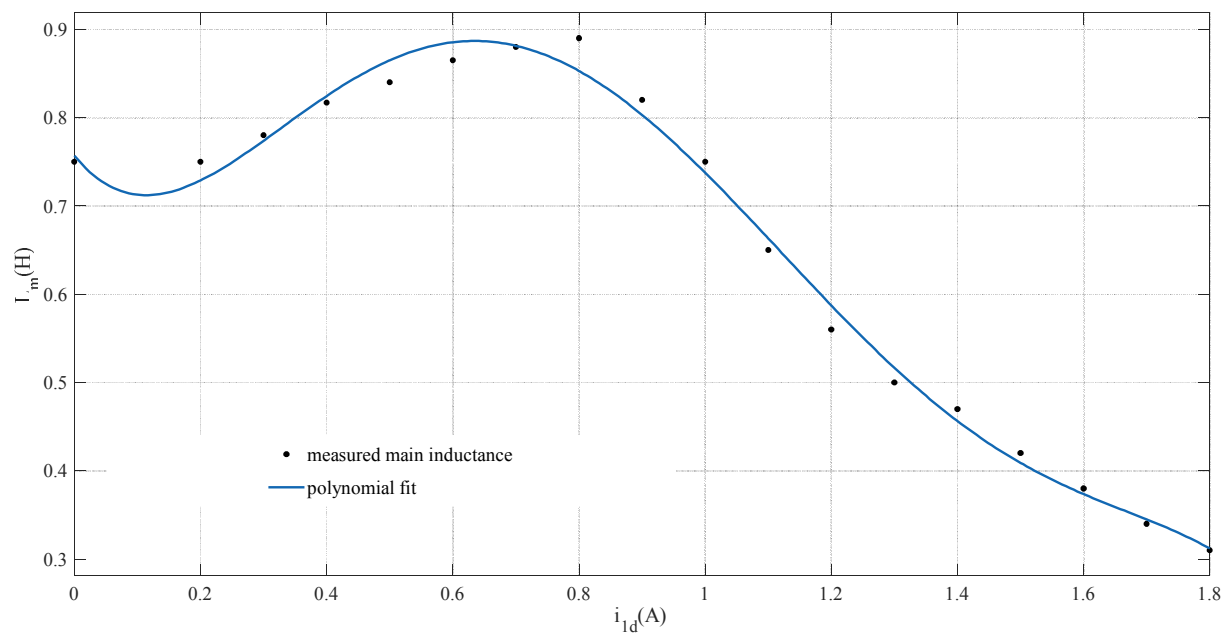

Figure 1 - Measured main inductance dependence and its polynomial approximation for a 370-W motor 
«Системні технології» 5 (130) 2020 «System technologies»

Main idea. Let us consider a certain case of load torque disturbance on the induction machine shaft. Assume that before a perturbation in the motor torque of magnitude $\Delta T_{\text {load }}$ the motor operates in the optimal mode of power consumption. It is obvious that after a change in the torque $T_{\mathrm{e}}$ on the shaft to the new value $T_{\mathrm{e}}+\Delta T_{\text {load }}, \Delta T_{\text {load }} \geqslant 0$, the speed controller will increase the reference of the torque-producing current in order to maintain the speed at a given level. Consider two boundary modes of behavior of the system under a change in the load torque on the motor shaft illustrated in Fig. 2:

1. The rotor flux linkage stays unvaried.

2. The rotor flux linkage is set to its new optimum steady-state value.

In the first case, the torque-producing current rapidly increases to its steady-state value, but under the new value of the torque on the shaft, the power consumption will not be optimal. In the second case, if we consider the peak value of the power losses during the transient period in Fig. 2 its value will be much greater than in case 1 . It was noticed that the field regulator attempts to establish a new steady-state optimal value for the rotor flux linkage as quickly as possible and as a result uses a high magnitude of the field-producing current and reaches its output almost in no time. This is the main contribution to short-term high losses according to the stepwise approach denoted in Fig. 2a. This fact means that it is not profitable to use solely the conventional flux controller in dynamic mode, due to high instantaneous power loss overshoots under changing torques and, in addition, it leads to the increase of the total energy consumed per duty cycle. That is, the peak power loss is much lower in case 1. This statement is also based on the fact that by condition there is no change in the rotor flux linkage before the change in load occurs. Thus, at the very first instance of time, the speed controller sets up the torque-producing current for the value of the rotor flux, which was optimal until any changes in the torque. 
«Системні технології» 5 (130) 2020 «System technologies»
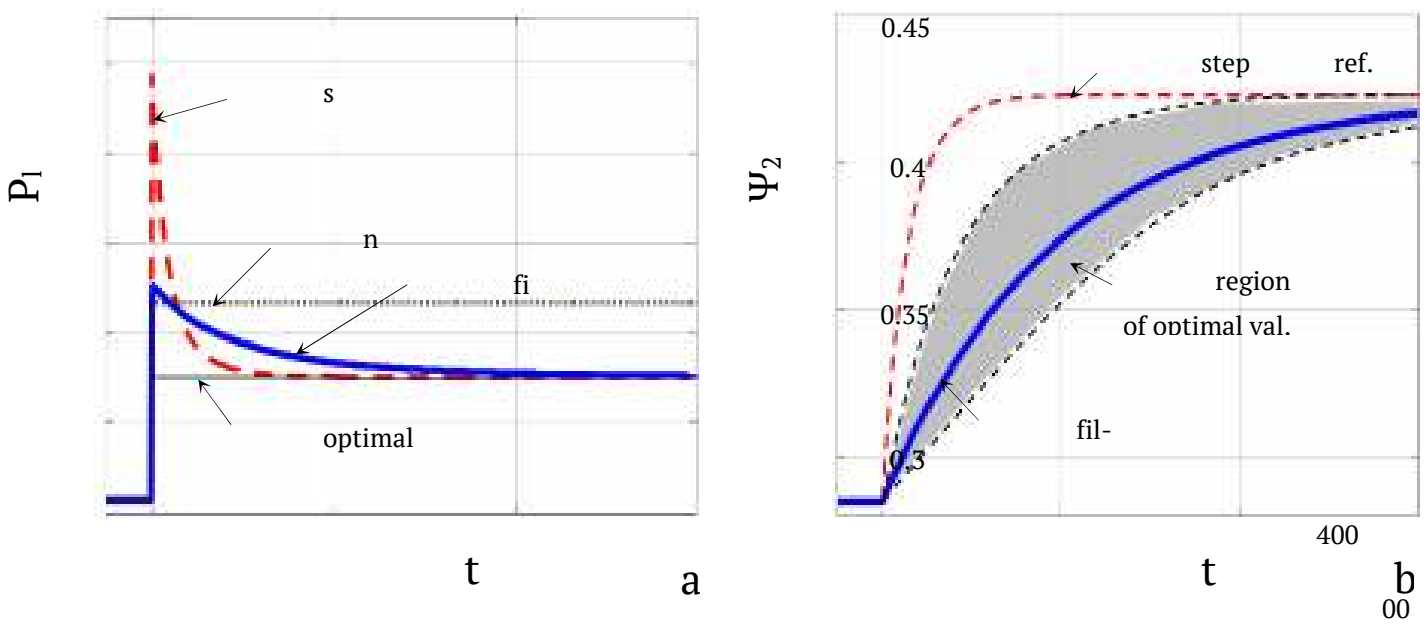

Figure 2 - $\mathrm{a}$ - power losses plot; $\mathrm{b}$ - rotor flux linkage trajectories

As illustrated in Fig. 2 this peak in the power losses can be significantly decreased by filtering the flux reference value using an appropriately chosen filter time constant.

The main idea of the proposed method is to combine approaches stepwise and nominal using low-pass filtering of the rotor flux linkage reference, implemented by a first-order system in Fig. 4. In order to give the user an easy to apply design criterion the filter time constant is given as a fraction of the rotor time constant of the considered motor. As illustrated in Fig. 2 this approach reduces the peak power loss under a change in load torque on the shaft of the motor and it converges to the optimal steady-state value.

Numerical study. Let us consider the impact of first-order filtering. To simplify the calculations, we will assume in the sequel that the flux regulator is fast enough such that the flux linkage follows its reference closely. In addition, assume that the speed and current controllers of field-oriented control have high enough performance to ensure the control characteristic close to perfectly rigid, that is, the dynamics of the stator phasor components is significantly higher than the dynamics of the magnetic flux and speed. In this case, we can assume for the flux linkage dynamics the first-order differential equation:

$$
\dot{\Psi}_{2}(t)=-\frac{1}{T_{\Psi}} \Psi_{2}(t)+\frac{1}{T_{\Psi}} \Psi_{2, \text { ref }}(t)
$$


and its input receives a step signal $\Psi_{2 \text {,ref }}(t)=\Psi_{2, \text { opt }}^{\text {ss }} \cdot 1(t)$ with $\Psi_{2, \text { ppt }}^{\text {ss }}$ as a reference signal corresponding to new operating conditions. The task is to find the time evolution of the outputs $\Psi_{2}(t)$, which in this case is a step response. Let us solve this problem with the help of transfer functions and signal images according to Laplace transform. Applying the Laplace transform to the left and right sides of (10), assuming that all the initial conditions are zero. The resulting equation is a complex function with a complex variable of the input $X[s]$ and output $\Psi[\mathrm{s}]$ :

$$
s \Psi[s]+\frac{1}{T_{\Psi}} \Psi[s]=\frac{1}{T_{\Psi}} X[s] .
$$

Thus, under zero initial conditions, the output of the object is calculated as the product of its transfer function by the image representation of the input

$$
\Psi[s]=W[s] \cdot X[s]=\frac{1}{T_{\Psi} s+1} \cdot \frac{\Psi_{2, \mathrm{opt}}^{\mathrm{ss}}}{s}=\frac{\Psi_{2, \mathrm{opt}}^{\mathrm{ss}}}{s}-\Psi_{2, \mathrm{opt}}^{\mathrm{ss}} \frac{1}{s+1 / T_{\Psi}} .
$$

Now, using the principle of superposition for images, we calculate the original output signal:

$$
\begin{aligned}
\Psi_{2}(t) & =\Psi_{2, \mathrm{opt}}^{\mathrm{ss}} L^{-1}\left\{\frac{1}{s}\right\}-\Psi_{2, \mathrm{opt}}^{\mathrm{ss}} L^{-1}\left\{\frac{1}{s+1 / T_{\Psi}}\right\}= \\
& =\Psi_{2, \mathrm{opt}}^{\mathrm{ss}}\left[1-\exp \left[-t / T_{\Psi}\right]\right]
\end{aligned}
$$

The solution of this differential equation for non-zero initial conditions is given by

$$
\Psi_{2}(t)=\Psi_{2}(0) \exp \left[-t / T_{\Psi}\right]+\Psi_{2, \text { opt }}^{\text {ss }}\left[1-\exp \left[-t / T_{\Psi}\right]\right]
$$

From this point, the expression (14), as well as new stator phasor component dynamics, are substituted into the time integral of power losses that is the energy loss

$$
\begin{aligned}
& J=\int_{0}^{T}\left[\frac{3}{2}\left(R_{1}+R_{2}\right) i_{1 \mathrm{~d}}^{2}(t)+\frac{3}{2}\left(R_{1}+R_{2}\right) i_{1 \mathrm{q}}^{2}(t)+\right. \\
& \left.+\frac{3}{2} \frac{R_{2}}{L_{\mathrm{m}}^{2}\left(i_{1 \mathrm{~d}}(t)\right)} \Psi_{2}^{2}(t)-3 \frac{R_{2}}{L_{\mathrm{m}}\left(i_{1 \mathrm{~d}}(t)\right)} \Psi_{2}(t) i_{1 \mathrm{~d}}(t)\right] d t
\end{aligned}
$$


«Системні технології» 5 (130) 2020 «System technologies»

with $T$ as the duration of the transient process. The example of calculated trajectories for an 11-kW motor is shown in Fig. 3. The duration of transients was chosen 1.4 sec.
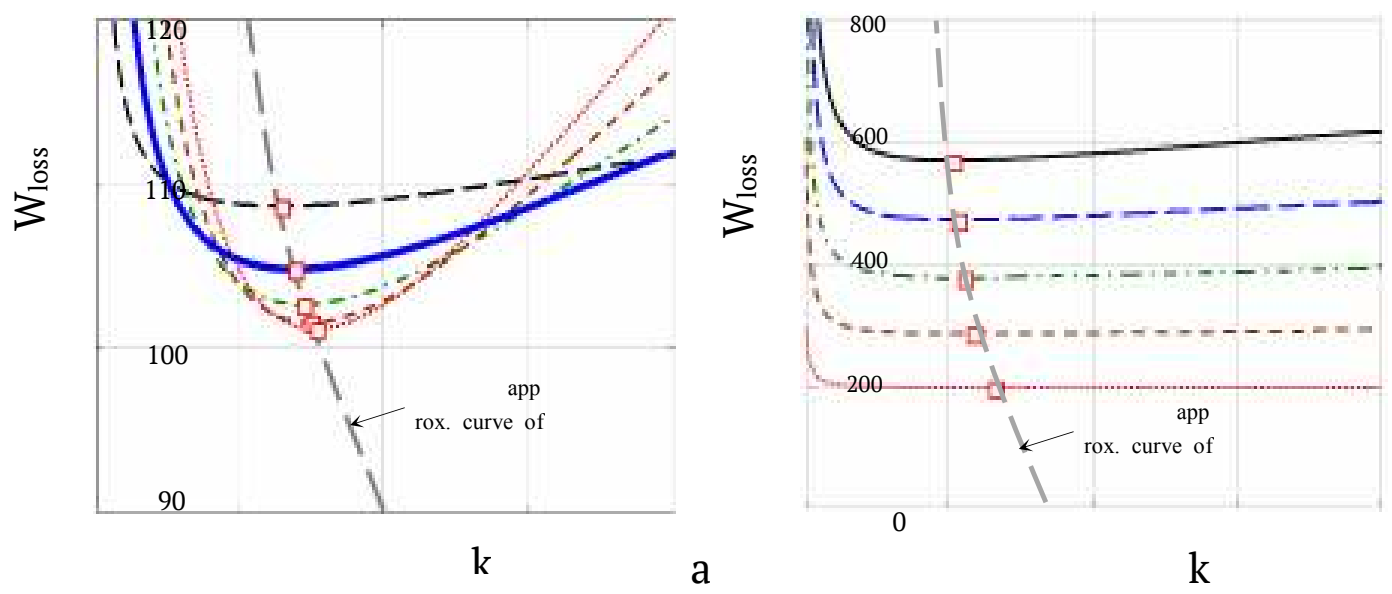

b)

Figure 3 - Calculated trajectories for loss energy: $a$ - step decrease; $b$ - step increase for an 11-kW motor

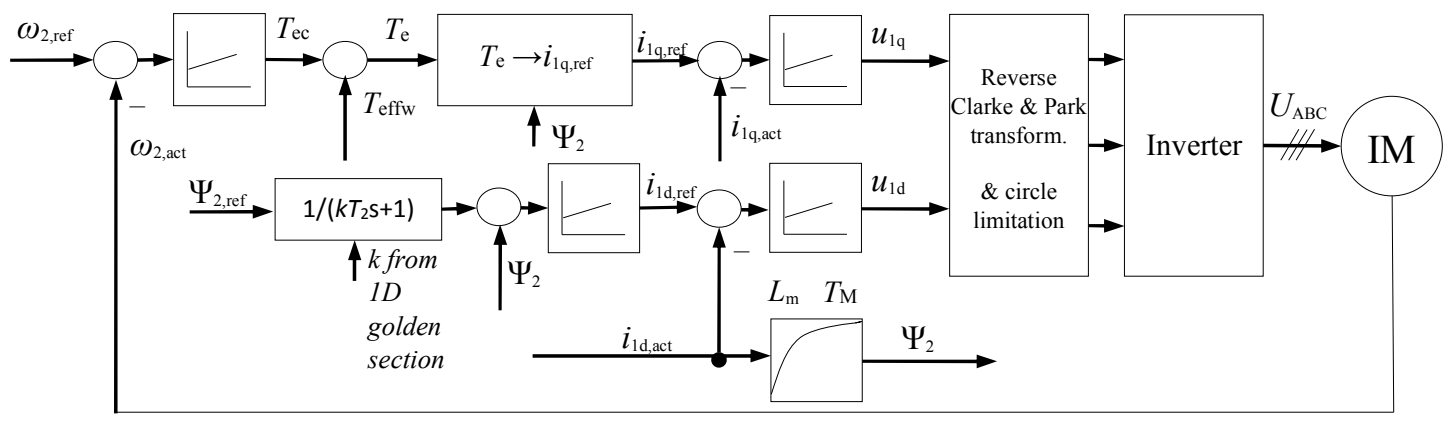

Figure 4 - Control structure

The first example was done for different load steps with decreasing load from $100 \%$ and below to $25 \%$ of the nominal motor torque. The results for the loss of energy are given in Fig. 3a. The first test was performed for different load steps with increasing load from $25 \%$ up to $100 \%$ of nominal motor torque. The obtained values of the energy losses as a function of $k$ are presented in Fig. 3b. It can be seen that for different load change conditions there is an appropriate minimizing vale for the multiplier $k$. To sum up, the most reasonable choice is in bounds $k \in[0.51]$.

Adaptive line search. In contrast to [7], where filter time constant with factor $k$ had fixed value over wide operation range, it is suggested in the 


\section{«Системні технології» 5 (130) 2020 «System technologies»}

current paper to effectively search the minimum point of the loss trajectories at each sampling period. According to the extreme value theorem in a formulation due to Weierstrass, a real-valued function $J$ is continuous on the closed interval $k \in[0.51]$, then $J$ attains its maximum and a minimum, each at least once.

Expression (15) is the one-dimensional case $k \in \mathbb{R}$. Then the function $J: \mathbb{R} \rightarrow \mathbb{R}$, the derivative of which is complicated or unknown. To find the optimal value of factor $k$, it is necessary to solve the problem of unconditional minimization $J \rightarrow$ min, taking into account that the function has a single minimum (concave) on the closed interval $k \in[0.51]$. It is assumed that the function is being positively defined $J(k) \in \mathbb{R}^{+}$. One of the most common search methods is the gradient descent method, which is formulated in a continuous time frame as follows:

$$
\dot{x}=-k \frac{d f}{d x}
$$

with $k>0$ as a constant value.

Denote $\mathrm{y}=f(\mathrm{x})$ and $\mathrm{x}_{\min }$ - minimum value of the function $f$ on a closed interval $[a, b], \dot{f}(\mathrm{x})=d f / d \mathrm{x}$. Let us prove that the method converges to a local minimum. For this purpose, a following Lyapunov function $V(y)=y^{2}$. Obviously, $V(\mathrm{y}) \in \mathbb{R}^{+}$. Differentiation over time gives

$$
\dot{V}(\mathrm{y})=2 \mathrm{y} \cdot \dot{\mathrm{y}}=2 \mathrm{y} \cdot \dot{f}(\mathrm{x}) \dot{\mathrm{x}}=-2 k \cdot f(\mathrm{x}) \cdot[\dot{f}(\mathrm{x})]^{2},
$$

$\dot{V}(\mathrm{y})<0$ everywhere, except $\mathrm{y}_{\min }=f\left(\mathrm{x}_{\min }\right)$ where $\dot{f}\left(\mathrm{x}_{\min }\right)=0$ and $\dot{V}\left(\mathrm{y}_{\min }\right)=0$. Thus, following the definition of stability according to Lyapunov, point $\mathrm{x}_{\min }$, i.e. the optimal value of $k$ is stable.

The search for the minimum point of the loss trajectories (Fig. 3) is done by means of a 1-D search method. At each sampling period, the golden section method is applied to search the loss-minimizing factor $k$, which represents the fraction of the rotor time constant.

Findings. A loss-minimizing flux control method based on filtering the rotor flux linkage reference for the flux regulator has been proposed in this paper. The main idea is to determine an appropriate filter time constant 
«Системні технології» 5 (130) 2020 «System technologies»

as a fraction of the rotor time constant using a multiplier $k$ by means of a 1-D search method taking into consideration the main inductance saturation. The result of a numerical study shows that the optimal value of the multiplier $k$ is in a range between 0.5 and 1 . This solution is simple to implement and can be easily integrated into existing inverters, and not less importantly, the same algorithm is used both to minimize power loss in statics and dynamics when load and speed conditions are changing.

\section{REFERENCES}

1. Bazzi, A., \& Krein, P. (2009). A Survey of real-time power-loss minimizers for induction motors. IEEE Electric Ship Technologies Symposium, ESTS 2009. 98-106.

2. Diachenko, G. G., \& Aziukovskyi, O. O. (2020). Review of methods for energy-efficiency improvement in induction machines. Naukovyi Visnyk Natsionalnoho Hirnychoho Universytetu, 1.

3. Windisch, Th., \& Hofmann, W. (2018). A novel approach to MTPA tracking control of AC drives in vehicle propulsion systems. IEEE Transactions on Vehicular Technology, 67(10), 9294-9302.

4. Plathottam, S. J., \& Salehfar, H. (2017). Transient energy efficiency analysis of field oriented induction machines. IEEE Access, 5, 20545-20556.

5. Klenke, F. \& Hoffmann, W. (2011). Energy-efficient control of induction motor servo drives with optimized motion and flux trajectories. Proceedings of the 14th European Conference on Power Electronics and Applications, 1-7. 6. Diachenko, G., Aziukovskyi, O., Rogoza, M., \& Yakimets, S. (2019). Optimal field-oriented control of an induction motor for loss minimization in dynamic operation. 2019 International Conference on Modern Electrical and Energy Systems (MEES), 94-97. Kremenchuk, Ukraine.

7. Diachenko, G., \& Schullerus, G. (2015). Simple dynamic energy efficient field oriented control in induction motors. Proceeding of the 18th International Symposium on Power Electronics. Novi Sad, Serbia.

Регулятор безперервної оптимізації енергоефективності

Received 02.03.2020. Accepted 06.03.2020.

в векторно-керованих асинхронних приводах

у цій роботі розглядається адаптивний вибір постійної часу фільтра для фільтрації стаціонарного сигналу завдання потоку ротора в задачі енергоефективного керування асинхронними машинами з векторним керуванням в перехідних режимах, коли умови навантаження та швидкості змінюються з урахуванням ефекту основного насичення магнітопроводу. Показано, що при належному керуванні швидкістю зміни потоку ротора втрати енергії за повний цикл роботи при зміні крутного моменту можна значно зменшити порівняно зі звичайними випадками. Аналіз відповідного вибору постійної часу фі- 
«Системні технології» 5 (130) 2020 «System technologies»

льтра як частки постійної часу ротора базується на чисельному дослідженні та результатах моделювання для трьох різних індукційних машин з різною потужністю.

\section{A continuous energy-efficiency optimization controller for field-orientation induction motor drives}

Abstract. The current paper discusses the adaptive choice of a filter time constant for filtering the steady-state flux reference in the energy-efficient control problem of field-orientation induction machines in transient behavior when load and speed conditions are changing taking into account the effect of the main induction saturation. It is shown that by appropriately managing the flux linkage rate of change the energy losses per full operation cycle under torque changes can be significantly reduced compared to the conventional cases. The analysis for the appropriate choice of the filter time constant as a fraction of the rotor time constant is based on a numerical study and simulation results for three different induction machines with different rated powers.

Дяченко Григорий Григорьевич - методист высшей категории, магистр, Национальный технический университет «Днепровская политехника».

Азюковский Александр Александрович - доцент, к.т.н., Национальный технический университет «Днепровская политехника».

Дяченко Григорій Григорійович - методист вищої категорії, магістр, Національний технічний університет «Дніпровська політехніка».

Азюковський Олександр Олександрович - доцент, к.т.н., Національний технічний університет «Дніпровська політехніка».

Diachenko Grygorii - Methodist of the highest category, M. S., Dnipro University of Technology.

Aziukovskyi Oleksandr - Associate professor, Ph. D., Dnipro University of Technology. 